\title{
Mechanistic evaluation of the sorption properties of endocrine disrupting chemicals in sewage sludge biomass
}

\author{
*A. O. Ifelebuegu; S. C. Theophilus; M. J. Bateman \\ Department of Geography, Environment and Disaster Management, Coventry University, Coventry, CV1 5FB, UK \\ Received 29 March 2010; $\quad$ revised 5 June 2010; accepted 18 July 2010; $\quad$ available online 1 September 2010
}

\begin{abstract}
This study investigated the sorption behaviour of two endocrine disrupting chemicals; $17 \beta$-estradiol (E2) and $17 \beta$-ethinylestradiol and their thermodynamic properties in an activated sludge biomass. The partition coefficient values measured for E2 and EE2 at varying temperatures range from 245 - $604 \mathrm{~L} / \mathrm{kg}$ ( $\log \mathrm{K}_{\mathrm{d}} 2.39$-2.78) and 267 - 631 $\mathrm{L} / \mathrm{kg}\left(\log \mathrm{K}_{d} 2.43-2.80\right)$, respectively. The $K_{d}$ values were inversely related to temperature. The average percentages of E2 and EE2 adsorbed to the solid phase at $4.3 \%$ dry solid were $87.2 \%$ and $92.5 \%$, respectively. Sorption of E2 and EE2 to the activated sludge biomass was found to be spontaneous and entropy retarded with $\Delta \mathrm{G}$ values in the range of -13 to $-16 \mathrm{KJ} / \mathrm{mol}$ and $\Delta \mathrm{S}$ value of $-105.2 \mathrm{~J} / \mathrm{mol} / \mathrm{K}$ and $96.7 \mathrm{~J} / \mathrm{mol} / \mathrm{k}$ for $\mathrm{E} 2$ and EE2, respectively. The enthalpy changes for E2 and EE2 were $-45.7 \mathrm{KJ} / \mathrm{mol}$ and $-43.4 \mathrm{KJ} / \mathrm{mol}$ respectively, demonstrating that the sorption process is exothermic. The values of the enthalpy changes also show that the mechanism of sorption is physisorption with some element of chemisorption.
\end{abstract}

Keywords: Enthalpy; Entropy; Partitioning coefficient; Sludge; Sorption

\section{INTRODUCTION}

The endocrine disrupting effects of certain chemicals found in sewage effluent and sludge continue to be a major issue of scientific interest, political and public concern. The steroid estrogens particularly estrone (E1), $17 \beta$-estradiol (E2) and 17 $\beta$-ethinylestradiol (EE2) have been detected in sewage effluents, sludge and receiving rivers across the globe (Huang and Sedlak, 2001; Nakada et al., 2006; Gomez et al., 2007; Kanda and Churchley, 2008; Combalbert and Hernandez -Raquet, 2010; Plosz et al., 2010; Rosal et al., 2010). E2 and EE2 are also very significant in terms of their estrogenic activity as they are among the most potent endocrine disruptors (Jobling et al., 1998). Various research efforts have shown that removal of these steroid hormones in activated sludge is predominantly through biological degradation, as well as sorption onto solids (Andersen et al., 2003; Langford and Lester, 2003; Ying et al., 2003; Kreuzinger et al., 2004; Ifelebuegu et al., 2006; Bonin and Simpson, 2007; Hashimoto and Murakami, 2009; Chen and Hu, 2009; Kumar et al., 2009; Schaar et al., 2010; Stasinakis et al., 2010). The sorption behaviour of

《A $*$ Corresponding Author Email: a.ifelebuegu@coventry.ac.uk Tel.: +44 2476888 355; Fax: +44 2476888400 these compounds in wastewater treatment can be predicted to a large extent by the partitioning coefficient values (Lai et al., 2000; Schwazenbach et al., 2003; Ternes et al., 2004; Andersen et al., 2005; Keenan et al., 2008). An understanding of the partitioning of the steroid hormones between the solid and the aqueous phases of an activated sludge biomass, as well as the mechanics of the sorption process is essential to understand the fate of these compounds in the unit processes of a wastewater treatment plant and their route into the environments when the biosolids are used for agricultural purposes.

The sorption isotherms describe the relationship between the solid and the aqueous phases from which the partitioning coefficients are determined (Abdel-Ghani and Elchaghaby, 2007; Yoochatchaval et al., 2008; Abdel-Ghani et al., 2009; Chen et al., 2010). Previous studies have examined partitioning coefficients of a number of organics (Soltanali and Hagani, 2008; Gong et al., 2009). Ternes et al. (2004) conducted a series of batch tests using sewage sludge to determine partitioning coefficients $\left(\mathrm{K}_{\mathrm{d}}\right)$ for a number of pharmaceuticals and personal care products. They found that $\log \mathrm{K}_{\mathrm{d}}$ values 
of the compounds ranged from 0 to 2.7 with EE2 having a $\log \mathrm{K}_{\mathrm{d}}$ value of 2.5. Clara et al., (2004) found that the $\log \left(\mathrm{K}_{\mathrm{d}}\right)$ for steroid estrogens were in the ranges of 2.64 2.97 and 2.71-3.00 for E2 and EE2, respectively. Andersen et al. (2005) determined distribution coefficients, $K_{\mathrm{d}}$ with activated sludge biomass for the steroid estrogens estrone, E2 and EE2 in batch experiments and they found $\log K_{\mathrm{d}}$ values of 2.6, 2.7, 2.8, respectively. Ren et al., 2007 studied the adsorption of EE2 on inactivated sludge and they found that the process was spontaneous and enthalpy driven. Similar observations were also made by Feng et al.,(2010).

This study focused on determining the partitioning ofE2 and EE2 in a blended primary and secondary sludge from a conventional activated sludge plant and evaluating the thermodynamic properties of the sorption process. These are important parameters in modeling of the sorption of steroid hormones to activated sludge biomass, as well as numerically evaluating sorption as a mechanism of removal of steroid hormones. E2 and EE2 were chosen for research experiments as they represent both natural and synthetic estrogens, respectively. The study was carried out in 2009 at the Coventry University Environmental Science Laboratory in the UK.

\section{MATERIALS AND METHODS}

Materials and reagents

E2 and EE2 were used as the model solute for this research. They were purchased from Sigma Aldrich (UK). All reagents used were all of HPLC grade provided from Fischer Scientific (UK). The aqueous solution of E2 and EE2 were prepared by dissolving the required amounts in methanol.

\section{Sewage sludge}

The sludge samples used for this research were obtained from a UK sewage treatment plant treating wastewater for a population equivalent of 381,000 . The plant consists of a conventional activated sludge plant with ferric dosing for phosphorus removal. The primary and secondary sludge were sampled and blended for the partitioning experiments. Previous research studies have shown that the $K_{d}$ values for the partitioning of steroid hormones are similar for both primary and secondary sludge from an activated sludge plant (Ternes et al., 2004). The measured percentage dry solid of the blended sludge was $4.3 \%$ with a COD/TSS of $99 \%$, TOC of $28.14 \%$ and a pH of 6.8 . The homogenised sludge was used without any $\mathrm{pH}$ adjustment and was treated to abiotic conditions by autoclaving at $120{ }^{\circ} \mathrm{C}$ for $25 \mathrm{~min}$ to inhibit any biological action during the batch experiments.

\section{Sorption experiments \\ Sorption equilibrium}

In the initial step, the sorption equilibrium was determined. $50 \mathrm{~mL}$ of the homogenised sludge spiked with approximately $1 \mathrm{mg} /$ Lwas stirred in a glass flask at $120 \mathrm{rpm}$ for $2 \mathrm{~h}$ to determine the time to reach equilibrium. Samples were withdrawn at intervals for analysis.

\section{Batch experiments}

Batch equilibrium experiments were used to determine sorption coefficients of the E2 and EE2 on the mixed sludge. $50 \mathrm{~mL}$ of sludge aliquots were added into $250 \mathrm{~mL}$ glass flasks with mix standard solutions of E2 and EE2 at concentrations ranging from 500 to $2500 \mu \mathrm{g} / \mathrm{L}$. To achieve equilibration, the mixtures were stirred using a magnetic stirrer for $2 \mathrm{~h}$ and centrifuged at $4000 \mathrm{rpm}$ for $15 \mathrm{~min}$ to separate the aqueous phase from the sludge. The sludge was then filtered and the supernatant solutions were removed and analyzed for the equilibrium concentrations of each endocrine disrupting chemicals (EDCs). The solid phase EDCs concentrations were determined on mass balance basis. The experiments were conducted at varying temperatures of $15^{\circ} \mathrm{C} 20^{\circ} \mathrm{C}, 25^{\circ} \mathrm{C}$ and $30^{\circ} \mathrm{C}$. The batch experiments were conducted in duplicates with two blank samples spiked with the solvent. The amount of each EDC adsorbed was calculated as the difference between the initial concentration and the equilibrium concentration of EDC in solution. The sludge/aqueous partition coefficient $\left(\mathrm{K}_{\mathrm{d}} \mathrm{L} / \mathrm{kg}\right)$ for each compound were calculated using the relationship:

$$
K_{d}=\frac{C_{s}}{C_{a q}}
$$

Where $C_{\mathrm{s}}$ is the concentration of EDC adsorbed by sludge in $\mathrm{mg} / \mathrm{kg}$ and while Caq is the concentration of the compound in aqueous phase in $\mathrm{mg} / \mathrm{L}$

\section{The percentage of EDC adsorbed to sludge}

The percentage of EDC adsorbed to sludge and that left in the liquid phase were also determined using Eq. 2.

$\% E D C_{s}$ in sludge $=\frac{C_{s}}{C_{\text {total }}} * \frac{100}{1}$

Where the concentration in the solid phase is $C_{s}$, while $C_{\text {total }}$ is the sum of the concentration in the aqueous and the solid phase. 


\section{Determination of thermodynamic properties}

The experimental data obtained were used to determine the thermodynamic feasibility of the sorption process. The concentrations used are higher than the actual levels in sewage sludge however; it has been shown that thermodynamic properties of sorption process are concentration independent (Annamalai and Puri, 2002). For the determination of "H and "S a plot of $\ln \mathrm{K}_{\mathrm{d}}$ against $1 / \mathrm{T}$ was done and the values determined from the slope and intercept of the plot according to the Eq. 3

$\ln K d=-\left(\frac{\Delta H}{R}\right)\left(\frac{1}{T}\right)+\frac{\Delta S}{R}$

Where, $\mathrm{R}$ is the gas constant $(8.314 \mathrm{~J} / \mathrm{mol} / \mathrm{K})$ and $T$ is the temperature in Kelvin.

$\Delta G$ was obtained at the various temperatures from Eq. 4.

$\Delta G=\Delta H-T \Delta S$

\section{Analytical procedures}

SPE clean Up of extracts

The extracts (supernatant) from the centrifuged aqueous solution were passed through a clean-up process by SPE using LC-18 cartridges set up on a SPE vacuum manifold after pre-conditioning. The cartridges were conditioned with $5 \mathrm{~mL}$ of acetone, $5 \mathrm{~mL}$ of methanol and $5 \mathrm{~mL}$ of D.I water at a flow rate of $5 \mathrm{~mL} / \mathrm{min}$. The sample was then loaded at about $5 \mathrm{~mL} / \mathrm{min}$ and subsequently washed with $10 \mathrm{~mL}$ of D.I water. Thereafter, the vacuum system was used to dry the cartridges for $45 \mathrm{~min}$. The analytes was then eluded from the SPE cartridges with $10 \mathrm{~mL}$ acetone. The extracts obtained were concentrated to an approximate volume of $1 \mathrm{~mL}$ under a gentle stream of nitrogen and then reconstituted with Methanol: $\mathrm{H}_{2} \mathrm{O} 55: 45(\mathrm{v} / \mathrm{v})$ to a final volume of $2 \mathrm{~mL}$ for HPLC analysis.

\section{Analysis of EDCs}

A Perkin-Elmer LS-50 Luminescence spectrometer was used to determine the wavelength range of the estrogens and Fluorescence detector wavelengths of $280 \mathrm{~nm}$ (excitation) $310 \mathrm{~nm}$ (emission) were selected based upon fluorescence peaks observed during excitation-emission matrix (EEM) analysis of the compounds in the HPLC eluent. Similar wavelengths were recorded by Van Emmerik et al., (2003) and Yoon et al., (2003). The HP 1050 HPLC -System consisted of a 79852A Quaternary Pump equipped with a 79855A 21-vial position autosampler, a G1303A vacuum helium degasser, computer and monitor, chemstation, 7125 injector valve and a 1046A fluorescence detector, using methanol and water of a 55:45 ratio as mobile phase. The analysis was conducted for $14 \mathrm{~min}$, with peaks for E2 and EE2 eluting at 9.5 and 10.5 min, respectively. The methods detection limit was evaluated as described in method USEPA (1984). MDL were 800 $\mathrm{ng} / \mathrm{L}$ and $845 \mathrm{ng} / \mathrm{L}$ for E2 and EE2, respectively.

\section{RESULTS AND DISCUSSION}

\section{Sorption equilibrium}

The time for the aqueous phase to reach equilibrium was established as previously described. The apparent equilibrium time was under one hour as shown in Fig. 1. The aqueous concentration remained unchanged in the last hour of the test.

\section{Sorption isotherms of E2 and EE2}

The partitioning of the compounds between the aqueous and solid phase was assumed to follow a linear isotherm with finite transfer rate as demonstrated by Schafer et al. (2002). The result represented in Figs. 2 and 3 shows that sorption of E2 and EE2 onto the activated sludge was well described by linear regression similar to the Freundlich isotherm model.

\section{Partition coefficients}

The slope of the isotherms represents the partition coefficients. $K_{d}$ values measured for E2 and EE2 at varying temperatures were within the range of 245 $604 \mathrm{~L} / \mathrm{kg}\left(\log \mathrm{K}_{\mathrm{d}} 2.39-2.78\right)$ and $267-631 \mathrm{~L} / \mathrm{kg}\left(\log \mathrm{K}_{\mathrm{d}}\right.$ $2.43-2.80)$ respectively. Detailed values and their corresponding correlation coefficients are presented in Table 1. Previous studies have also reported adsorption coefficients within this range. Ternes et

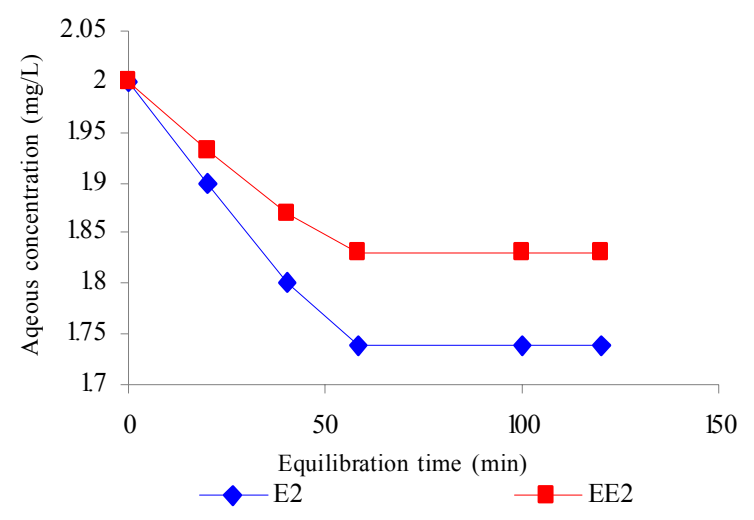

Fig. 1: Concentration of E2 and EE2 in the aqueous phase over time for the determination of time to reach equilibrium 


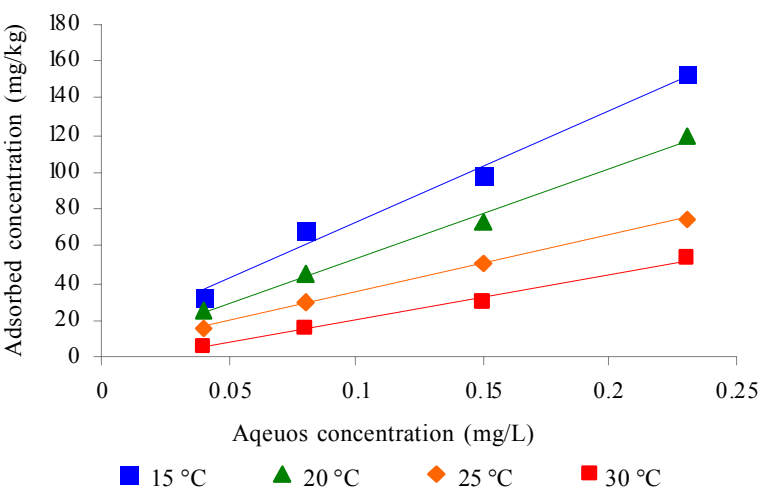

Fig. 2: E2 sorption isotherm for the blended sludge at varying temperatures for the determination of partitioning coefficients

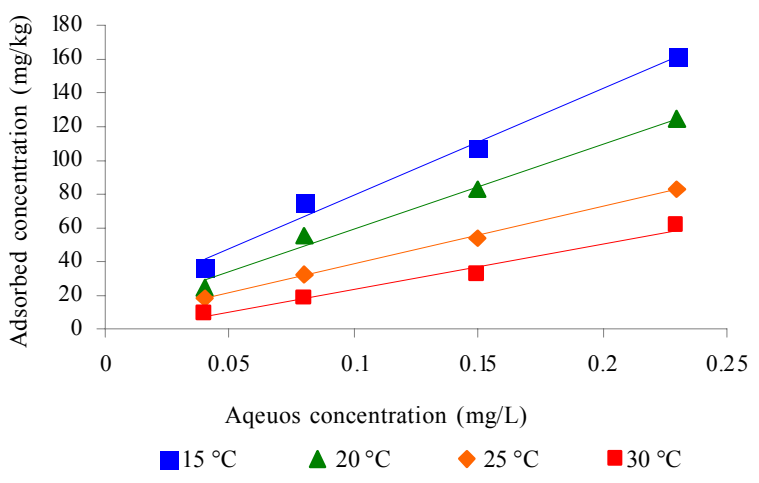

Fig. 3: EE2 sorption isotherm for the blended sludge at varying temperatures for the determination of partitioning coefficients

al. (2004) reported $\mathrm{K}_{\mathrm{d}}$ values for EE2 as 278-379 L/kg. Similar values were also obtained by Andersen et al. (2005). This study also demonstrates that the partitioning coefficients are inversely related to temperature.

\section{The percentage of EDC adsorbed to sludge}

The percentage of EDC adsorbed to sludge and that left in the liquid phase were also determined using Eq. 2. The average percentages of E2 and EE2 adsorbed to the solid phase at $4.3 \%$ dry solid were $87.2 \%$ and $92.5 \%$, respectively. A similar study by Keenan et al. (2008) reported a $>90 \%$ sorption rate of estrogens to the solid phase. Also, Ivashechkin et al. (2004) investigated Radioactive-labelled BPA and showed that over $75 \%$ of BPA in sludge was bound to solids ( $\log K_{\mathrm{d}}=2.09-2.30$; $\left.\log K_{\mathrm{oc}}=2.72-3.11\right)$. The high sorption rate of E2 and EE2 to the solid phase can be attributed to the high hydrophobicity of their functional group and the higher $\%$ dry solid of the homogenized sludge blend. EE2
Table 1: Partitioning coefficients of E2 and EE2 at varying temperatures

\begin{tabular}{cccc}
\hline \multirow{2}{*}{ E2 } & Temperature $\left({ }^{\circ} \mathrm{C}\right)$ & $\mathrm{K}_{\mathrm{d}}(\mathrm{L} / \mathrm{Kg})$ & $\mathrm{r}^{2}$ \\
\cline { 2 - 4 } & 15 & 604 & 0.987 \\
& 20 & 487 & 0.996 \\
& 25 & 312 & 0.998 \\
& 30 & 245 & 0.995 \\
EE2 & 15 & & \\
& 20 & 631 & 0.988 \\
& 25 & 508 & 0.990 \\
& 30 & 337 & 0.998 \\
& & 267 & 0.981 \\
\hline
\end{tabular}

Table 2: Gibbs free energy of sorption for E2 and EE2

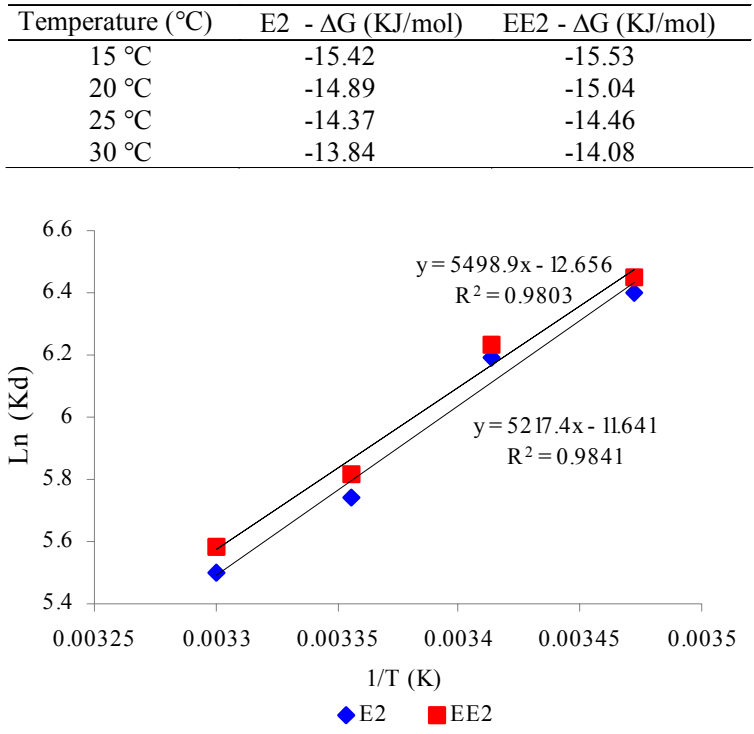

Fig. 4: Plot of $\ln \mathrm{K}_{\mathrm{d}}$ versus inverse of temperature for enthalpy and entropy change determination

showed a higher affinity to the solid phase, this could explain while EE2 is more recalcitrant compared to E2 and other natural estrogens during the wastewater treatment process.

\section{Thermodynamic properties}

The natural logarithm of the $\mathrm{K}_{\mathrm{d}}$ values obtained from the linear regressions in Figs. 2 and 3 were plotted against the inverse of temperature. The plot Fig. 4 gave a linear relationship with correlation coefficient of 0.980 for E1 and 0.984 for EE2. Enthalpy and entropy changes were obtained from Eq. 3 from which the Gibbs free energy of the sorption of the compounds were computed. The Gibbs free energy at the different temperatures is presented in Table 2. The "G values are in the range -13 to $-16 \mathrm{KJ} / \mathrm{mol}$. Similar values were obtained by Feng et 
al. (2010) and this demonstrates that the sorption of E2 and EE2 to the activated sludge biomass is spontaneous. The enthalpy changes for E2 andEE2 were $-45.7 \mathrm{KJ} / \mathrm{moland}$ $-43.4 \mathrm{KJ} / \mathrm{mol}$, respectively, demonstrating that the sorption process is exothermic. The values of the enthalpy changes also suggest that sorption is likely both physisorption and chemisorption. According to Weber and DiGiano (1996), the heat of adsorption for physisorption is in the range of $5-20 \mathrm{KJ} / \mathrm{mol}$ while that of chemisorptions is in the region of $100-400 \mathrm{KJ} / \mathrm{mol}$. The enthalpy values are between the two ranges indicating that the mechanism is predominately physisorption mechanism with some chemical adsorption as the enthalpy values are closer to the physisorption range. The entropy changes were $-105.2 \mathrm{~J} / \mathrm{mol} / \mathrm{K}$ for $\mathrm{E} 2$ and $-96.7 \mathrm{~J} \mathrm{~mol} / \mathrm{K}$ for EE2 implying that the sorption of $\mathrm{E} 2$ and $\mathrm{EE} 2$ to conventional activated sludge biomass is entropy retarded. This barrier is however, superseded by the enthalpy changes.

\section{CONCLUSION}

The following conclusions can be drawn from this study:

- The average percentages of E2 and EE2 adsorbed to the solid phase at $4.3 \%$ dry solid were $87.2 \%$ and 92.5 $\%$, respectively with EE2 showing a slightly higher affinity to the solid phase.

- The "G values are in the range -13 to $-16 \mathrm{KJ} / \mathrm{mol}$. This demonstrates that the sorption of E2 and EE2 to the activated sludge biomass is spontaneous.

- $\mathrm{K}_{\mathrm{d}}$ values measured for E2 and EE2 at varying temperatures were within the range of $245-604 \mathrm{~L} / \mathrm{kg}$ $\left(\log \mathrm{K}_{\mathrm{d}} 2.39-2.78\right)$ and $267-631 \mathrm{~L} / \mathrm{kg}\left(\log \mathrm{K}_{\mathrm{d}} 2.43-\right.$ 2.80), respectively.

- This study has also demonstrated that the partitioning coefficients were inversely related to temperatures.

- The enthalpy changes for E2 and EE2 were - $45.7 \mathrm{KJ} /$ mol and $-43.4 \mathrm{KJ} / \mathrm{mol}$ respectively, demonstrating that the sorption process is exothermic. The values of the enthalpy changes also suggest that the mechanism of sorption is predominantly physisorption and some elements of chemisorption.

- The entropy changes were $-105.2 \mathrm{~J} / \mathrm{mol} / \mathrm{K}$ for E2 and $-96.7 \mathrm{~J} / \mathrm{mol} / \mathrm{K}$ for EE2 implying that the sorption of E2 and EE2 to conventional activated sludge biomass is entropy retarded which is superseded by the enthalpy changes.

\section{ACKNOWLEDGEMENTS}

The authors wish to express their gratitude to the staff at Coventry University Environmental Science Laboratory for their support during the laboratory sessions and the financial and material support provided by the Department of Geography, Environment and Disaster Management of Coventry University.

\section{REFERENCES}

Abdel Ghani, N.; Elchaghaby, G. A., (2007). Influence of operating conditions on the removal of $\mathrm{Cu}, \mathrm{Zn}, \mathrm{Cd}$ and $\mathrm{Pb}$ ions from wastewater by adsorption., Int. J. Environ. Sci. Tech., 4 (4), 451-456 (6 pages).

Abdel-Ghani, N. T.; Hegazy, A. K.; El-Chaghaby, G. A., (2009). Typha domingensis leaf powder for decontamination of aluminium, iron, zinc and lead: Biosorption kinetics and equilibrium modeling. Int. J. Environ. Sci. Tech., 6 (2), 243-248 (6 pages).

Andersen, H.; Siegrist, H.; Halling-Sorensen, B.; Ternes, T. A., (2003). Fate of estrogens in a municipal sewage treatment plant. Environ. Sci. Tech., 37 (18), 4021-4026 (6 pages).

Andersen, H. R.; Hansen, M.; Kjolholt, J.; Stuer-Lauridsen, F.; Ternes, T.; Halling-Sorensen, B., (2005). Assessment of the importance of sorption for steroid estrogens removal during activated sludge treatment. Chemosphere, 61 (1), 139-146 (8 pages).

Annamalai, K.; Puri, K. I., (2002). Advanced Thermodynamics Engineering. Boca Raton, FL, CRC Press.

Bonin, J. L.; Simpson, M. J., (2007). Sorption of steroid estrogens to soil and soil constituents in single- and multi-sorbate systems. Environ. Toxic. Chem., 26 (12), 2604-2610 (7 pages).

Chen, X.; Hu, J., (2009). Degradation of $17 \beta$-estradiol and its conjugates: Effects of initial concentration and MLSS Concentration. Process Biochem., 44 (12), 1330-1334 (5 pages).

Chen, D. Z.; Zhang, J. X.; Chen, J. M., (2010). Adsorption of methyl tert-butyl ether using granular activated carbon: Equilibrium and kinetic analysis. Int. J. Environ. Sci. Tech., 7 (2), 235-242 (8 pages).

Clara, M.; Strenn, B.; Saracevic, E.; Kreuzinger, N., (2004). Adsorption of bisphenol-A, 17â-estradiol and 17á-ethinylestradiol to sewage sludge. Chemosphere, 56 (9), 843-851 (22 pages).

Combalbert, S.; Hernandez-Raquet, G., (2010). Occurrence, fate, and biodegradation of estrogens in sewage and manure. Appl. Microbiol. Biotech. 86 (6), 1671-1692 (22 pages).

Feng, Y.; Zhang, Z.; Gao, P.; Su, H.; Yu, Y.; Ren, N., (2010). Adsorption behaviour of $\mathrm{EE}_{2}(17 \alpha$-ethinylestradiol) onto the inactivated sewage sludge: Kinetics, thermodynamics and influence factors. J. Hazard. Mater., 175 (1-3), 970-976 (7 pages)

Gomez, M. J.; Martinez Bueno, M. J; Lacorte, S.; Fernandez-Alba, A. R.; Aguera, A., (2007). Pilot survey monitoring pharmaceuticals and related compounds in a sewage treatment plant located on the Mediterranean coast. Chemosphere, 66 (6) 993-1002 (10 pages)

Gong, R.; Liang, J.; Chen, J.; Huang, F., (2009). Removal of bisphenol A from aqueous solution by hydrophobic sorption of hemimicelles Int. J. Environ. Sci. Tech., 6 (4), 539-544 (6 pages).

Hashimoto, T.; Murakami, T., (2009). Removal and degradation characteristics of natural and synthetic estrogens by activated sludge in batch experiments. Water Res., 43 (3), 573-582 (10 pages).

Huang, C. H.; Sedlak, D. L., (2001). Analysis of estrogenic hormones in municipal wastewater effluent and surface water using enzyme-linked immunosorbent assay and gas 
chromatography/tandem mass spectroscopy. Environ. Toxicol. Chem., 20 (1), 133-139 (7 pages).

Ifelebuegu, A. O.; Lester, J. N.; Churchley, J.; Cartmell, E., (2006). Removal of an endocrine disrupting chemical $(17 \alpha-$ ethyloestradiol) from wastewater effluent by activated carbon. Environ. Tech., 27 (12), 1343-1349 (7 pages).

Ivashechkin, P.; Corvini, P. F. -X.; Dohmann, M., (2004). Behaviour of endocrine disrupting chemicals during the treatment of municipal sewage sludge. Water Sci. Tech., 50 (5), 133-140 (8 pages).

Jobling, S.; Nolan, M.; Tyler, C. R.; Brighty, G. C.; Sumpter, J. P., (1998). Widespread sexual disruption in wild fish. Environ. Sci. Tech., 32 (17), 2498-2506 (9 pages).

Kanda, R.; Churchley, J., (2008). Removal of endocrine disrupting chemicals during conventional wastewater treatment. Environ. Tech., 29 (3), 315-323 (9 pages).

Keenan, H. E.; Sakultantimetha, A.; Bengkedphol, S.,(2008) Environmental fate and partition co-efficient of oestrogenic compounds in sewage treatment process. Environ. Res., 106 (3), 313-318 (6 pages).

Kreuzinger, N.; Clara, M.; Strenn, B.; Kroiss, H., (2004). Relevance of the sludge retention time (SRT) as design criteria for waste water treatment plants for the removal of endocrine disruptors and pharmaceuticals from waste water. Water Sci. Tech., 50 (5), 149-156 (8 pages).

Kumar, A. K.; Mohan, S. V.; Sarma, P. N., (2009). Sorptive removal of endocrine-disruptive compound 9estriol, E(3) from aqueous phase by batch and column studies: kinectic and mechanistic evaluation. J. Hazard. Mater., 164 (2-3), 820828 (9 pages)

Lai, K. M.; Johnson, K. L.; Scrimshaw, M. D.; Lester, J. N., (2000). Binding of waterborne steroid estrogens to solid phases in river and estuarine systems. Environ. Sci. Tech., 34 (18), 3890-3894 (5 pages).

Langford, K.; Lester, J. N., (2003). Fate and behaviour of endocrine disrupters in wastewater treatment processes. In: Birkett, J. W. and Lester, J. N., (Eds.), Endocrine Disrupters in Wastewater and Sludge Treatment Processes, Lewis Publishers and IWA Publishing, London, UK.

Nakada, N.; Tanishima, T.; Shinokara, H.; Kiri, K.; Takada, H., (2006). Pharmaceutical chemicals and endocrine disrupters in municipal wastewater in Tokyo and their removal during activated sludge treatment. Water Res., 40 (17), 3297-3303 (7 pages).

Plósz, B. G.; Leknes, H.; Liltved, H.; Thomas, K. V., (2010). Diurnal variations in the occurrence and the fate of hormones and antibiotics in activated sludge wastewater treatment in Oslo, Norway. Sci. Total Environ., 408 (8), 1915 -1924 (10 pages).
Ren, Y.; Nakano, K.; Nomura, M.; Chiba, N.; Nishimura, O., (2007). A thermodynamic analysis on adsorption of estrogens in activated sludge process. Water Res., 41 (11), 2341-2348 (8 pages).

Rosal, R.; Rodríguez, A.; Perdigón-Melón, J. A.; Petre, A.; GarcíaCalvo, E.; Gómez, M. J.; Agüera, A.; Fernández-Alba, A. R., (2010). Occurrence of emerging pollutants in urban wastewater and their removal through biological treatment followed by ozonation. Water Res., 44 (2), 578-588 (11 pages).

Schaar, H.; Clara, M.; Gans, O.; Kreuzinger, N., (2010). Micropollutant removal during biological wastewater treatment and a subsequent ozonation step. Environ. Pollut., 158 (5), 1399 -1404 (6 pages).

Schafer, A. I.; Mastrup, M.; Lund Jensen, R., (2002). Particle interaction and removal of trace contaminants from water and wastewaters. Desalination, 147 (1-3), 243-250 (8 pages).

Schwarzenbach, R. P.; Gschwend, P. M.; Imboden, D. M., (2003). Environmental Organic Chemistry. Wiley, New York.

Soltanali, S.; Shams Hagani, Z., (2008). Modeling of air stripping from volatile organic compounds in biological treatment processes. Int. J. Environ. Sci. Tech., 5 (3), 353-360 (8 pages).

Stasinakis, A. S.; Kordoutis, C. I.; Tsiouma, V. C.; Gatidou, G.; Thomaidis, N. S., (2010). Removal of selected endocrine disrupters in activated sludge systems: Effect of sludge retention time on their sorption and biodegradation. Bioresour. Tech., 101 (7), 2090-2095 (6 pages).

Ternes, T. A.; Herrmann, N.; Bonerz, M.; Knacker, T.; Siegrist, H.; Joss, A., (2004). A rapid method to measure the solidwater distribution coefficient $(\mathrm{Kd})$ for pharmaceuticals and musk fragrances in sewage sludge. Water Res., 38 (19), 40754084 (10 pages).

USEPA, (1984). Definition and procedure for the determination of MDL: Revision 1.11, Fed. Rg, 49, 43430 - 43431.

Van Emmerik, T.; Angove, M. J.; Johnson, B. B.; Wells, J. D.; Fernandes, M. B., (2003). Sorption of 17ß-estradiol onto selected soil minerals. J. Coll. Inter. Sci., 266 (1), 33-39 (7 pages).

Weber Jr., W. J.; DiGiano, F. A., (1996) Process dynamics in environmental systems. Wiley Publishers, New York.

Ying, G.; Kookana, R. S.; Dillon, P., (2003). Sorption and degradation of selected five endocrine disrupting chemicals in aquifer material. Water Res., 37 (15), 3785-3791 (7 pages).

Yoochatchaval, W.; Ohashi, A; Harada, H.; Yamaguchi, T.; Syutsubo, K., (2008). Characteristics of Granular Sludge in an EGSB Reactor for Treating low Strength Wastewater. Int. J. Environ. Res., 2 (4), 319-328 (10 pages).

Yoon, Y.; Westerhoff, P.; Snyder S. A.; Esparza M., (2003). HPLC-fluorescence detection and adsorption of bisphenol A, $17 \beta$-estradiol, and $17 \hat{a}$-ethynyl estradiol on powdered activated carbon. Water Res., 37 (14), 3530-3537 (8 pages).

\section{AUTHOR (S) BIOSKETCHES}

If elebuegu, A. O., M.Sc., M.Eng., Department of Geography, Environment and Disaster Management, Coventry University, Coventry, CV1 5FB, United Kingdom. Email: a.ifelebuegu@coventry.ac.uk

Theophilus, S. C., M.Sc., Department of Geography, Environment and Disaster Management, Coventry University, Coventry, CV1 5FB, United Kingdom. Email: theophilussc@yahoo.co.uk

Bateman, M. J., Ph.D., Department of Geography, Environment and Disaster Management, Coventry University, Coventry, CV1 5FB, United Kingdom. Email: m.bateman@coventry.ac.uk

How to cite this article: (Harvard style)

Ifelebuegu, A. O.; Theophilus, S. C.; Bateman, M. J., (2010). Mechanistic evaluation of the sorption properties of endocrine disrupting chemicals in sewage sludge biomass. Int. J. Environ. Sci. Tech., 7 (4), 617-622. 